\title{
DIALLEL ANALYSIS OF LITTER SIZE AND BODY WEIGHT IN RATS
}

\author{
J. L. JINKS \\ A.R.C. Unit of Biometrical Genetics, Department of Genetics, \\ University of Birmingham \\ and \\ P. L. BROADHURST \\ Institute of Psychiatry, Maudsley Hospital, University of London
}

\section{INTRODUCTION}

Received 7.ii.63

THE diallel cross method of assessing potential breeding material, which has been used for some forty years in plant breeding, has found no comparable place in animal breeding. Yet the advantages of this breeding programme apply equally to both plant and animal material especially now that much of animal breeding is directed towards the development of inbred strains and the testing of strains for their usefulness in increasing productivity by intercrossing. The following analysis of litter size and body weight in a diallel set of crosses among six inbred strains of rats show the value that this approach can have in practice.

\section{MATERIAL}

The origin of the six inbred strains of rats (Rattus norvegicus, Berkenhout) used and details of their maintenance and husbandry have been given by Broadhurst (1960). Some behavioural characteristics of these strains and of the $36 F_{1}$ 's produced from them by diallel crossing have already been described and analysed (Broadhurst, 1959, 1960). As part of the investigations the size of litters and their weights at birth were recorded and at 21 days of age (weaning) the pups were sexed and the total weight of the two sexes recorded separately. At 50 days and again a few days after 100 days of age each individual was weighed. It is with the analyses of these litter size and body weight data that we shall be concerned here.

\section{RESULTS \\ (i) Litter size}

The number of live births were recorded for each of the 72 litters produced by crossing the six inbred strains in all 36 combinations in duplicate. We have, therefore, a total of 71 degrees of freedom for differences between litters which may be partitioned as in table 1 . The analysis of variance based on this partitioning shows that only differences between the maternal strains (dams) have a significant effect $(\mathrm{P}<0 \cdot 00 \mathrm{I})$ on litter size. That is, we have evidence only for maternal determination of litter size at birth.

Changes in litter size due to deaths were recorded at 21,50 and Ioo days and at these ages the litters were also scored for the relative 
numbers of sons and daughters. At these ages, therefore, we can examine the changes in litter size and composition due to deaths. An analysis of variance of the angular transformed percentages of sons in the litters at 2I, 50 and Ioo days shows no differences between litters for this character and no significant deviation from a mean of 50 per cent. sons at any of these ages. After Ioo days 84 individuals out of an initial 670 live births had died. A $2 \times 2$ contingency analysis of the number of surviving and non-surviving members of the two sexes at Ioo days gave a non-significant value of $\chi^{2}$. There is, therefore, no differential mortality between the sexes. Furthermore, an analysis of variance of the angular transformed percentage survival at Ioo days shows no difference between litters. The deaths appear to occur at random between sexes and litters. It is not surprising, therefore, that the analysis of variance of litter size at Ioo days shows the same exclusively maternal determination which was observed at birth.

\section{(ii) Mean body weight of individuals}

From the weight and size of each of the 72 litters at birth we can obtain the average body weight of individuals in each litter. This will, of course, be averaged over sexes since the sexes were not weighed separately until 2 I days (table 3 ). An analysis of variance of the mean body weight of individuals at birth is given in table 3 . Unlike the similar analysis of litter size at birth (table I) this analysis shows

TABLE I

An analysis of variance of litter size at birth

\begin{tabular}{|c|c|c|c|c|}
\hline \multirow{2}{*}{ Source of variation } & \multirow{2}{*}{$\mathbf{N}$} & \multirow{2}{*}{ MS } & \multicolumn{2}{|c|}{ Pooled error } \\
\hline & & & VR & $\vec{P}$ \\
\hline $\begin{array}{l}\text { M. Maternal strains (Dams) } \\
\text { P. Paternal strains (Sires) } \\
\text { M } \times \text { P } \\
\text { Duplicate litters }\end{array}$ & $\begin{array}{r}5 \\
5 \\
25 \\
36\end{array}$ & $\left.\begin{array}{r}18 \cdot 7 \\
4 \cdot 5 \\
4 \cdot 2 \\
3 \cdot 4\end{array}\right\}^{3} \cdot 76^{*}$ & $\begin{array}{l}5 \cdot 0 \\
1 \cdot 2\end{array}$ & $\begin{array}{l}<0.001 \\
>0.20\end{array}$ \\
\hline
\end{tabular}

* Pooled error for $6 \mathrm{I}$ degrees of freedom.

that even at birth both the maternal and paternal strains have significant effects on the mean weight of their offspring, the maternal effect being somewhat the larger. Since at 2I, 50 and 100 days (table 2) the mean weights of individuals in each litter were recorded separately for the two sexes, an extended analysis of variance is possible for these data .hich includes items for sex differences and interactions with sex. This analysis, presented in table 3 , consists of two parts. The first part, in the top half of the table, includes all the between litter items which we recognised in the earlier analyses (tables $I$ and 3). The second part, contained in the lower half of the table, includes all the sex items which are within litter comparisons. 
The appropriate error term for the top half of the table is the usual duplicate litter mean square and for the lower half it is the interaction mean square between duplicate litters and $\operatorname{sex}(\mathrm{D} \times \mathrm{S})$.

TABLE 2

Individual body weight (in grams) at birth and maturity for the 36 kinds of families averaged over duplicate litters; pooled over sexes at birth and given separately for sexes at maturity

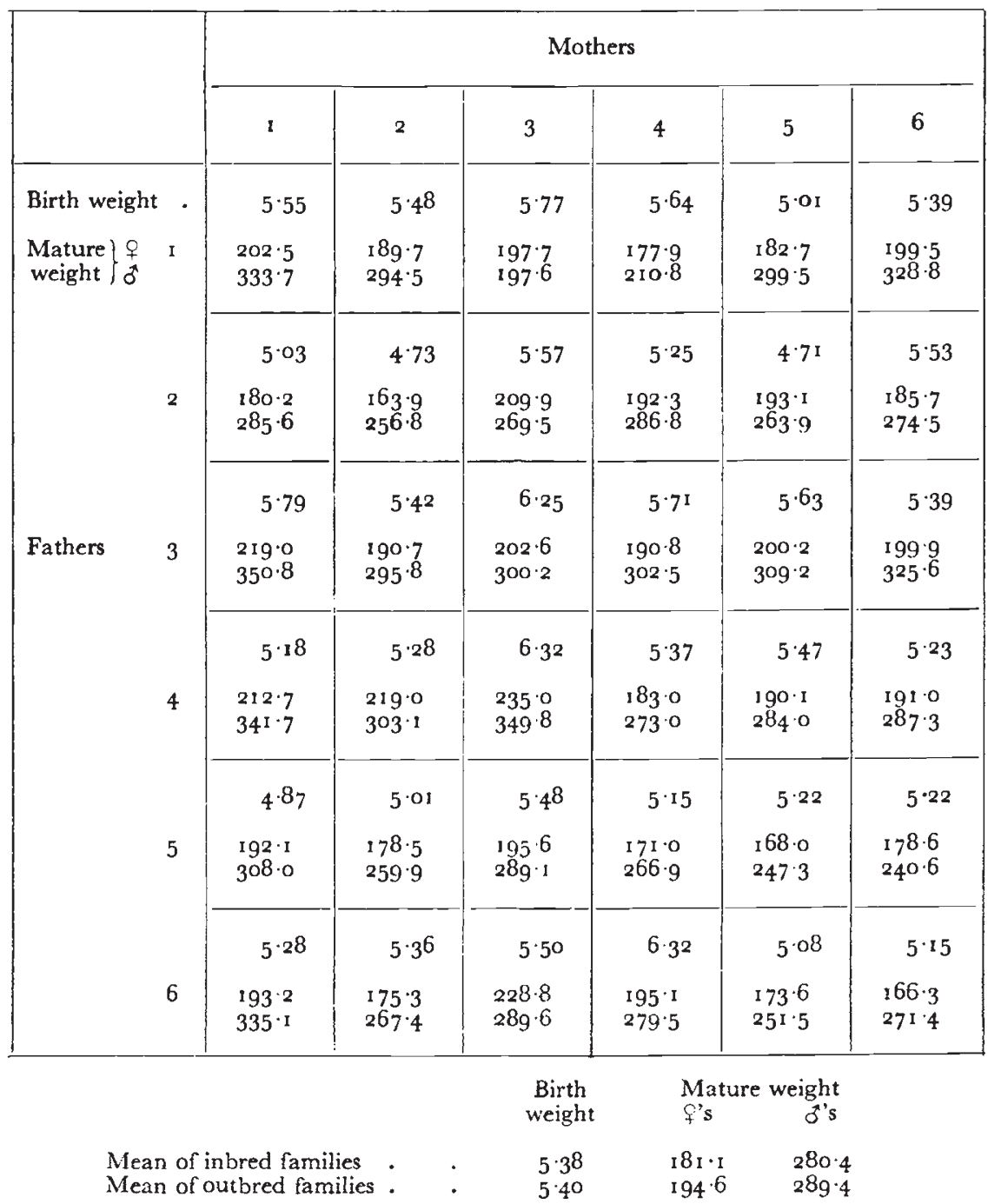

The sex difference is the only item in the analyses of the $2 \mathrm{I}, 50$ and roo day results which is consistently significant, the males being always the heavier. At 21 days no other item has a significant effect on the mean body weight of individuals. At 50 days there is a significant maternal influence and only at ıoo days do we return to the 
situation found at birth, namely, that both the maternal and paternal strains have a significant effect on this character. Hence these analyses reveal a remarkable situation in that apart from the differences between the sexes the control of the mean weight of individual rats is apparently determined by heritable agencies at certain ages and under the exclusive control of the mother's genotype and non-heritable agencies at others.

\section{TABLE 3}

An analysis of variance of mean body weight per individual rat at various ages

\begin{tabular}{|c|c|c|c|c|c|c|c|c|c|}
\hline \multirow{2}{*}{$\begin{array}{c}\text { Age } \\
\text { Source of variation }\end{array}$} & \multicolumn{3}{|c|}{ Birth } & \multicolumn{2}{|c|}{ 2I days } & \multicolumn{2}{|c|}{50 days } & \multicolumn{2}{|c|}{ I00 days } \\
\hline & N. & MS & VR & MS & VR & MS & VR & MS & VR \\
\hline $\begin{array}{l}\text { M. Maternal strain } \\
\mathrm{P} . \text { Paternal strain } \\
\mathrm{M} \times \mathrm{P} \\
\text { D. Duplicate litters }\end{array}$ & $\begin{array}{r}5 \\
5 \\
25 \\
36\end{array}$ & $\begin{array}{l}0.73 \\
0.55 \\
0.15 \\
0.14\end{array}$ & $\begin{array}{l}5 \cdot 21^{* * * *} \\
3.93^{*} \\
1 \cdot 07 \\
\quad \cdots\end{array}$ & $\begin{array}{r}49 \cdot 8 \\
42 \cdot 2 \\
73 \cdot 6 \\
\times 3^{1} \cdot 4\end{array}$ & $\begin{array}{l}\cdots \\
\cdots \\
\cdots \\
\cdots\end{array}$ & $\begin{array}{r}1368 \cdot 4 \\
333 \cdot 4 \\
357 \cdot 4 \\
35: 5\end{array}$ & $\begin{array}{l}3 \cdot 9^{* *} \\
\cdots \\
\cdots \\
\cdots\end{array}$ & $\begin{array}{r}4279 \\
4593 \\
724 \\
650\end{array}$ & $\begin{array}{l}6 \cdot 6 * * * \\
7 \cdot 1 * * * \\
1 \cdot 1 \\
\cdots\end{array}$ \\
\hline $\begin{array}{l}\text { S. Sex } \\
\mathbb{M} \times \mathbf{S} \\
\mathrm{P} \times \mathrm{S} \\
\mathrm{M} \times \mathbf{P} \times \mathbf{S} \\
\mathrm{D} \times \mathrm{S}\end{array}$ & $\begin{array}{r}1 \\
5 \\
5 \\
25 \\
36\end{array}$ & $\begin{array}{l}\cdots \\
\cdots \\
\cdots \\
\cdots\end{array}$ & $\begin{array}{l}\cdots \\
\cdots \\
\cdots \\
\cdots\end{array}$ & $\begin{array}{r}137 \cdot 9 \\
7 \cdot 0 \\
2 \cdot 9 \\
6 \cdot 9 \\
4 \cdot 2\end{array}$ & $\begin{array}{c}32 \cdot 8 * * * \\
1 \cdot 7 \\
\ldots \\
1.6 \\
\ldots\end{array}$ & $\begin{array}{r}42570 \cdot 0 \\
187.9 \\
35 \cdot 7 \\
30 \cdot 9 \\
60.8\end{array}$ & $\begin{array}{c}700 \cdot 5^{* * *} \\
3 \cdot 1 * \\
\cdots \\
\ldots \\
\cdots\end{array}$ & $\begin{array}{r}348503 \\
879 \\
1166 \\
241 \\
258\end{array}$ & $\begin{array}{c}349 \cdot 7^{* * *} \\
3 \cdot 5^{*} \\
4 \cdot 5^{* *} \\
\cdots \\
\cdots\end{array}$ \\
\hline
\end{tabular}

Probability: $0.05-0.01 *$

$0.01-0.001 * *$

$<0.001 * * *$

This conclusion has been confirmed by an alternative analysis of variance of these data, namely, the analysis of the diallel table proposed by Hayman (1954). In this analysis the mean weights of individuals at birth, 50 and 100 days show a heritable control involving both additive and dominance effects while at 2 I days there is no significant effect of any of the heritable components. At birth and I oo days the additive effect is highly significant $(\mathrm{P}<0.00 \mathrm{I})$, but at 50 days it is barely so $\left(P=0.05^{-0.01}\right)$. This analysis also surprisingly shows that the mean body, weights of individuals from reciprocal crosses do not differ significantly at any age.

There are two ways in which we can pursue the analysis of these data further. The first is to attempt a more detailed interpretation of the inheritance of the mean weight of individuals for those ages for which we have evidence of a heritable control of this character. The second is to combine the measurements of the mean body weights of individuals at different ages to obtain an estimate of their rates of increase in weight. We can then attempt to interpret the differences between litters in terms of heritable and non-heritable components of variation of this new metric. We shall now illustrate the use of both methods. 
Since there is significant heritable variation in the mean weights of individuals at birth, 50 and 100 days we can investigate the inheritance of this character further by the method proposed by Jinks and Hayman (Jinks and Hayman, I953; Jinks, 1954; Hayman, I954b).

(a)

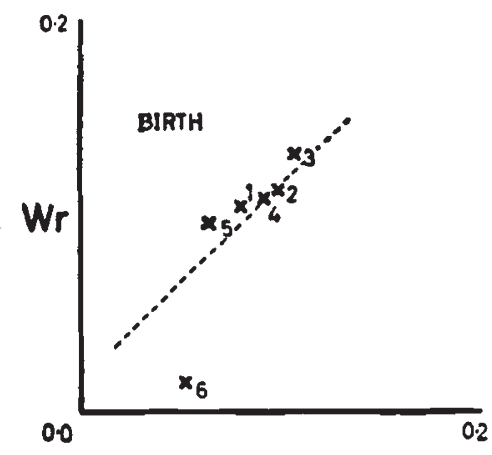

(c)

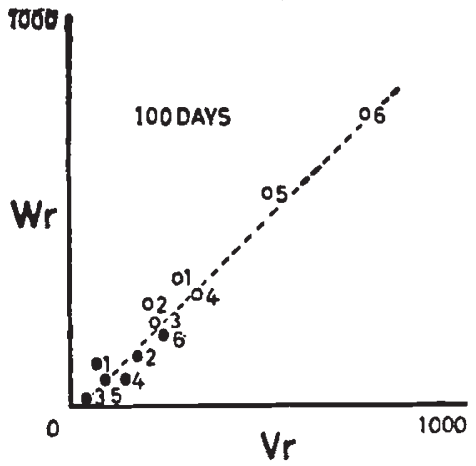

(b)

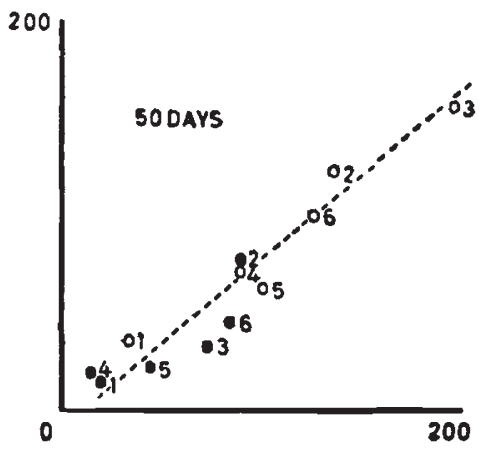

(d)

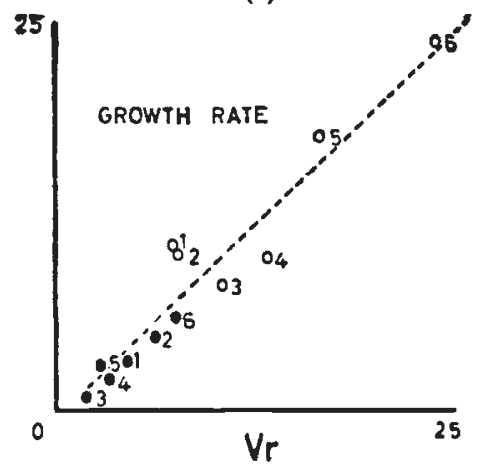

Fig. 1.-The regressions of $\mathrm{Wr}$ on $\mathrm{Vr} . \times$ denotes data pooled over sexes, $\bullet$ denotes females only, O males only. The dotted line is a slope of one through the mean.

1a. Individual body weight at birth. Although array 6 is off the slope of one the best fitting linear regression is not significantly different from this slope.

1b. Individual body weight at 50 days.

1c. Individual body weight at roo days.

1d. The linear rate of growth between birth and maturity on a transformed time scale.

The female array points always have the smaller scatter. The order of array points in $1 a, 1 b$ and $1 c$ differ hence the control of body weight differs with age.

This consists essentially in examining the relationship between the variance of arrays $(\mathrm{Vr})$ and covariance of arrays ( $\mathrm{Wr})$. Since there are no differences betv'een reciprocal crosses these were first averaged. For the birth weights : 1e Wr's and Vr's are for the means of the pooled sexes but for the 50 and Ioo day scores the Wr's and Vr's have been calculated separately for the two sexes. The graphs of $\mathrm{Wr}$ against $\mathrm{Vr}$ are presented in fig. $\mathrm{I} a, b$ and $c$.

The regressions of $\mathrm{Wr}$ on $\mathrm{Vr}$ are in all cases significant and in no 
case do they differ from unit slope. Thus we can detect no failure of the assumptions on which our interpretation is based which in this instance means we can assume the absence of significant effects of non-allelic interactions and of non-random distributions of genes among the six parental lines. Hence we can interpret the distribution of array points on the $\mathrm{Wr} / \mathrm{Vr}$ graphs solely in terms of additive and dominance components of variation. From the significance of the regressions we can conclude that dominance is present in all cases. Furthermore, since the regression lines pass through or close to the point of origin $\mathrm{Wr}=0, \mathrm{Vr}=0$, the level of dominance must be

\section{TABLE 4}

Components of variation of the individual body weights at birth, 50 and roo days of age

\begin{tabular}{|c|c|c|c|c|c|}
\hline \multirow{2}{*}{$\begin{array}{r}\text { Age } \\
\text { Component }\end{array}$} & \multirow[t]{2}{*}{ Birth } & \multicolumn{2}{|c|}{$5^{0}$ days } & \multicolumn{2}{|c|}{ I0o days } \\
\hline & & Males & Females & Males & Females \\
\hline $\begin{array}{c}\mathrm{D} \\
\mathrm{H}_{1} \\
\mathrm{H}_{2} \\
\mathrm{~F} \\
\mathrm{E}_{2} * \\
\text { Dominance ratio }\end{array}$ & $\begin{array}{l}0.2234 \\
0.1096 \\
0.0720 \\
0.0748 \\
0.0172 \\
0.70\end{array}$ & $\begin{array}{r}185 \cdot 2 \\
154 \cdot 8 \\
151 \cdot 8 \\
46 \cdot 4 \\
39 \cdot 1 \\
0 \cdot 91\end{array}$ & $\begin{array}{r}78 \cdot 5 \\
111 \cdot 3 \\
107 \cdot 2 \\
29 \cdot 3 \\
13 \cdot 0 \\
1 \cdot 19\end{array}$ & $\begin{array}{r}825 \cdot 3 \\
403 \cdot 6 \\
452 \cdot 6 \\
-273 \cdot 5 \\
89 \cdot 3 \\
0 \cdot 70\end{array}$ & $\begin{array}{r}273 \cdot 1 \\
281 \cdot 0 \\
239 \cdot 0 \\
75 \cdot 1 \\
24 \cdot 3 \\
1 \cdot 01\end{array}$ \\
\hline
\end{tabular}

* $E_{2}$ appropriate for the average of reciprocal and replicate litters.

almost complete. That is, the dominance component $\mathrm{H}_{1}$, must be almost as large as the additive component $\mathrm{D}$ and hence the dominance ratio $\sqrt{ } \mathrm{H}_{1} / \mathrm{D}$ (our estimate of the dominance level) must be close to unity.

We can, in fact, estimate these components and the level of dominance directly by the method of Jinks (1954). The values obtained for the birth, 50- and Ioo-day data are given in table 4 . These confirm that the level of dominance is close to unity. For the 50- and roo-day data the components of variation have been calculated separately for the males and females in the progenies. These confirm the higher level of variation among the males which is shown in the $\mathrm{Wr} / \mathrm{Vr}$ graphs by the greater linear scatter of the points for the males (fig. I $b$ and $c$ ). Both agree with the earlier analyses of variance which gave highly significant differences between sexes (table 3 ). Thus the analyses, so far, agree in indicating the presence of dominance for the character, mean body weight of individuals, at birth, 50 and 100 days in both sexes and a lower level of variation in the females.

The order of the array points on the $\mathrm{Wr} / \mathrm{Vr}$ graph indicates the relative number of dominant to recessive alleles in the common parents of the arrays, those with the most dominant allele being 
nearest the origin of the graph (Jinks, 1954). Examination of the three relevant $\mathrm{Wr} / \mathrm{Vr}$ graphs in fig. I $a-c$ shows that the order of the array points changes with age and sex. The changes with age are presumably significant in that there is a complete interchange of the extreme points $(6$ and 3 ) between birth and roo days. The changes with sex are, by comparison, minor. And four of the six array points, namely, $1,2,5$ and 6 at 50 days and $1,3,4$ and 6 at 100 days maintain their relative positions in the $\mathrm{Wr} / \mathrm{Vr}$ graphs for both sexes.

The changing order of the array points suggests that the genetical control of the mean weight of individuals changes with age. In fact the dominant alleles of the loci controlling this character at birth appear to be predominantly in strain 6 while the dominant alleles of the loci controlling the character at Ioo days appear to be predominantly in strain 3. Glearly, either different loci control the character at different ages or, alternatively, the same loci are always in control but the dominance relationships of their alleles change with age. Our analyses cannot draw a distinction between these alternative explanations. They do, however, allow us to draw further conclusions about this phenomenon. Thus examination of the graphs in the figure shows the changes in the relative positions of the array points occur gradually with age, their positions at 50 days (fig. $1 b$ ) being, in most cases, intermediate between those at birth (fig. Ia) and at 100 days (fig. 1c). Furthermore, the extreme array points show a greater alteration in their relative positions with age than do the intermediate ones. That is, parents which possess mostly dominant alleles at the loci controlling birth weight appear to possess mostly recessive alleles at the loci controlling weight at 100 days and viceversa. But parents having equal numbers of dominant and recessive alleles for birth weight also possess equal numbers for 10o-day weight. This is readily understandable on the assumption that the dominance relations of alleles at the same loci are gradually reversed with age. It is not so easy to understand this relationship, however, if completely different sets of loci control birth weight and roo-day weight of individuals.

While at the genotypic level the changes with age may be complex, at the phenotypic level they are quite simple. At birth, dominance is for animals of intermediate weight (like parent 6), both heavier and lighter animals are recessive (like parents 2 and 3 respectively). At maturity, however, dominance is for the heavier type of animal (like parent 3). Since, as a consequence, the relative weights of individuals in different crosses change between birth and maturity, the rate of increase in weight should be a useful metric for comparing crosses. Our second analysis, therefore, is directed towards making this comparison.

The regression of weight of individuals on age, in our data, is essentially linear between birth and 100 days. Nevertheless, the proportion of the variation in weight with age taken out by the linear 
regression on age is raised, on average, to 95 per cent. by taking 0 to 21,21 to 50 and 50 to roo days as equal time intervals. This transformation of the time scale which is approximately the same as taking the logarithms of time not only makes the linear regression coefficient a more useful metric for comparing the offspring of different crosses but it also considerably eases the calculation of this coefficient. It will be used, therefore, for all our remaining analyses.

Individuals were not weighed separately until they reached the age of 50 days hence the linear regressions were calculated from family means. Since, however, sexes were weighed separately from 21 days onwards the regression coefficients have been calculated independently for each sex. This has meant that the family means, averaged over both sexes, have been used for both sexes at birth. This assumes, of course, that at birth the sex difference is negligible. Back extrapolation of the magnitude of the sex difference at $2 \mathrm{I}, 50$ and 100 days to that expected at birth suggests that this assumption is not unreasonable.

The Wr, Vr graphs for males and females derived from the diallel tables containing the linear regression coefficients averaged over duplicate litters and reciprocal crosses are given in fig. Id. Both sets of data show a very good agreement with the expected linear regression line of unit slope. There is, therefore, no evidence of a failure of the usual assumptions on which our interpretation of these graphs will be based.

Since the $\mathrm{Wr}, \mathrm{Vr}$ graphs are linear and have unit slope differences in the rate of increase in weight (measured on our metric) must be partly due to additive and dominance components of variation. Furthermore, since the regression line passes close to the origin $(\mathrm{Vr}=0, \mathrm{Wr}=0)$ dominance is almost complete.

For both sexes strain 6 has the most recessive alleles at the loci controlling weight increase while strain 3 appears to have most of the dominant alleles. The remaining strains fall between these two extremes but their relative order varies somewhat between sexes. Examination of the regression coefficients shows that strain 3 produces the fastest growing female progeny. Hence the dominant alleles are those which produce a rapid increase in weight. Strains 2 and 6 produce the slowest growing female progeny. Hence the recessive alleles produce a slow increase in the weight of females. Similarly, strains I and 3 produce the fastest growing males so that the dominant alleles are responsible for rapid growth in male progeny. Strains 2, 5 and 6 all produce slow growing male progenies. In strains.5 and 6 it is the recessive alleles as usual which produce the slow growth (fig. Id). Thus, in general, dominant alleles produce a faster gain in weight than the recessive alleles at the same loci. This is in agreement with our earlier analyses of the mean weight of individuals (fig. I $a-c)$ which showed that the dominant alleles produce the heavier animals at maturity. 


\section{(iii) Maternal care and body weight}

The analyses of variance in table 3 show that at birth and at maturity the heritability of body weight in rats is high, at $2 \mathrm{I}$ days of age there is no detectable heritable variation and while at 50 days a heritable component has re-emerged it is predominantly maternal in origin. Clearly between birth and the end of weaning the initial differences in body weight among different genotypes disappear and are replaced by differences which are non-heritable in origin.

Two conditions obtain between birth and weaning which are absent at other times. First, each member of a litter is totally dependent on its mother for its nutrition and any other care it receives. Second, the density of animals in a cage and hence competition for space and maternal care is determined by the size of the litter, which in this experiment were not culled to a standard size. After weaning, however, the mother was removed and the litters were broken up to give a constant density of at first, five, and later three animals per cage until maturity (see Broadhurst, I96o, pp. 41-43 for details). Maternal care and litter size are therefore the obvious factors to examine in any attempt to explain the changes which occur in the control of body weight between birth and weaning. These two factors may not be independent. If maternal care is limiting, differences in litter size would largely determine the relative amount of care received by each member of the litter.

All the litters in a maternal array of a diallel set of crosses will be suckled by mothers from the same inbred strain. If maternal care is an important factor in determining body weight at weaning we would expect, therefore, that the offspring from litters of the same maternal array would be more alike than those from litters in different maternal arrays. We can test this expectation by comparing the mean square for differences between the six maternal arrays for 5 degrees of freedom (which is identical with the maternal strain mean square of table 3 ) with the mean square for differences among litters within the same maternal arrays for $5 \times 6=30$ degrees of freedom (which is the mean square obtained on pooling the sums of squares for paternal strains and the $\mathbf{M} \times \mathbf{P}$ interaction in table 3 ). Their values are 49.8 and $70^{\circ} 0$ respectively. Thus at weaning, the body weight of individuals from litters cared for by mothers from different strains differ no more than do individuals from litters whose mothers came from the same strains.

Might not the rate of growth of the individuals between birth and weaning be a more sensitive indicator of any effect of maternal care than the weight of individuals at the end of weaning? An analysis of variance of the increase in body weight between birth and weaning also fails to detect an effect of maternal care (mean square for differences between maternal arrays, $5^{1 \cdot 5}$; mean square for differences between litters within the same maternal arrays, 65.5). We have, therefore, no evidence that body weight at weaning 
is in any way influenced by the strain of mother. We may conclude, therefore, that maternal care is not a limiting factor in the determination of body weight. This agrees with the general conclusion from similar studies with mice (Brumby, 1960). The absence of a significant postnatal maternal effect on some behavioural characteristics of the rats used in this experiment and of others has previously been reported (Broadhurst, I96o, I96I). Our present conclusion, therefore, comes as no surprise. What is surprising, however, is that body weight at 50 days provides evidence of an effect of maternal care of the kind we have failed to find at weaning. At $5^{0}$ days the variation in body weight between maternal arrays is significantly in excess of that among different litters within the same maternal array $(\mathrm{P}=0.0 \mathrm{I}-0.00 \mathrm{r})$. If we accept this as evidence for differences in the maternal care provided by mothers from different inbred strains we should have to explain why this had no effect during the period of maternal care, but was detected later. On the other hand, unless we admit a delayed effect of maternal care we have the problem of explaining why there is a significantly greater difference between maternal arrays than within them in the period immediately after weaning but not at any other age.

Litter size, the second factor which might differentially affect the body weight of individuals in different litters is not independent of the first factor. Since all the significant differences in litter size occur between maternal arrays (table I) their contribution to differences between maternal arrays and between litters within maternal arrays is confounded with differences produced by the litters being cared for by mothers from different or from the same inbred strains, respectively.

In general, litter size and body weight are uncorrelated in our data. For example, the rate of growth from birth to maturity, on our transformed time scale, is quite independent of litter size $(r=$ -0.04). Similarly, the correlations between litter size and weight at birth and at weaning and the increase in body weight during this period are small and negative (table 5 , bottom row) and only significant $(\mathrm{P}=\mathrm{O} . \mathrm{OI})$ at birth. There is, therefore, a slight overall tendency for the weight of single individuals in a litter to increase as the size of that litter decreases, and vice-versa. This tendency is less pronounced at weaning than at birth. Hence competition between members of a litter for food and space does not appear to be an important factor in determining body weight or increase in body weight during the period of postnatal maternal care.

The correlations between litter size and weight at birth, weight at weaning and the increase in weight over the six maternal arrays are positive but not significant (table 5 ). The maternal strains clearly differ in the total weight of offspring they can produce and successfully feed (see also table 7). Thus the maternal strains with a high capacity can produce large litters without reducing the body weights of the 
individual pups. The same three correlations calculated for the differences between litters within maternal arrays were all negative and at birth and for the increase in weight they were significant $(\mathrm{P}<0.02)$. Hence within a maternal array, where all litters have mothers from the same inbred strain and, therefore, presumably the same heritable capacity, changes in litter size tend to lead to compensating changes in individual body weight. However, this compensation is less marked at weaning than at birth and it falls off

TABLE 5

Correlations between litter size and body weight at birth and at weaning and increase in body weight from birth to weaning

\begin{tabular}{|l|c|c|c|}
\hline \multirow{2}{*}{ Source of correlation } & \multicolumn{3}{|c|}{ Litter size and } \\
\cline { 2 - 4 } & Birth weight & Weaning weight & $\begin{array}{c}\text { Weight } \\
\text { increase between } \\
\text { birth and weaning }\end{array}$ \\
\hline Between maternal arrays . & +0.56 & +0.67 & +0.17 \\
Within maternal arrays . & -0.61 & -0.30 & -0.43 \\
Over all litters & -0.31 & -0.15 & -0.28 \\
\hline
\end{tabular}

very markedly with age. In fact, at maturity none of the values for the three correlations, corresponding to those compared in table 5 is greater than 0.08 . There is, therefore, evidence of an effect of litter size on body weight but this effect is confined to the prenatal period and to the increase in body weight in the postnatal period up to weaning. Hence we may ask whether the postnatal effect is merely a continuation, in an attenuated form, of the prenatal effect or whether the prenatal and postnatal effects are independent.

If for the different litters we compare the mean body weight of individuals from the same litter at birth and at weaning (2I days) we find that they are uncorrelated (table 6). In fact the correlations between body weight at birth and 50 days and birth and Ioo days are higher than that between birth and weaning. And all these correlations are small compared with those between weaning and $5^{\circ}$ days and 50 and 100 days. Hence the negative correlation we have observed between body weight and litter size within maternal arrays at weaning does not appear to be a continuation of a prenatal effect of litter size on body weight observed at birth. The negative correlation which develops between birth and weaning is apparently due to causes which operate specifically during this period.

While we have no entirely satisfactory explanation of the absence of heritable differences in body weight at weaning we can recognise 
two contributory causes. First, we have shown that individuals from different litters tend to be more alike in body weight if they are suckled by mothers from the same inbred line rather than by mothers from different inbred lines. This effect, however, can be demonstrated only three weeks after weaning. Second, there is a

TABLE 6

The correlations between the body weights of individuals at different ages

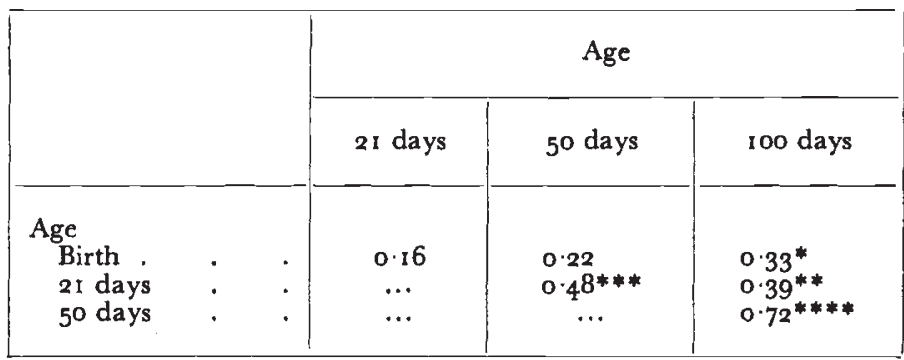

$$
\begin{aligned}
* \mathrm{P} & =0.05-0.02 \\
* * \mathrm{P} & =0.02-0.01 \\
* * * \mathrm{P} & =0.01-0.001 \\
* * * * \mathrm{P} & =<0.001
\end{aligned}
$$

smaller increase in weight between birth and weaning for individuals from larger litters relative to those from smaller litters within the same maternal array.

\section{(iv) Litter weights}

Litter weights, which are the products of the two characters already

\begin{tabular}{|c|c|c|c|c|c|}
\hline $\begin{array}{l}\text { Age } \\
\text { Source of variation }\end{array}$ & $\mathbf{N}$ & $\begin{array}{l}\text { Birth } \\
\text { MS }\end{array}$ & $\begin{array}{l}\text { 2I days } \\
\text { MS }\end{array}$ & $\begin{array}{c}50 \text { days } \\
\text { MS }\end{array}$ & $\begin{array}{c}\text { Ioo days } \\
\text { MS }\end{array}$ \\
\hline $\begin{array}{l}\text { M. Maternal strains } \\
\text { P. Paternal strains } \\
\mathbf{M} \times \mathbf{P} \\
\text { Duplicate litters }\end{array}$ & $\begin{array}{r}5 \\
5 \\
25 \\
36\end{array}$ & $\begin{array}{c}699 \cdot 0^{*} \\
56 \cdot 9 \\
76 \cdot 4 \\
72 \cdot 3\end{array}$ & $\begin{array}{l}12 \cdot 837^{*} \\
4 \cdot 772 \\
5 \cdot 328 \\
3 \cdot 268\end{array}$ & $\begin{array}{c}257 \cdot 560^{*} \\
56 \cdot 551 \\
87 \cdot 810 \\
71 \cdot 301\end{array}$ & $\begin{array}{l}790 \cdot 986 * \\
312 \cdot 452 \\
236 \cdot 353 \\
236 \cdot 377\end{array}$ \\
\hline
\end{tabular}
considered, litter size and individual body weight, are known for

TABLE 7

An analysis of variance of litter weights at various ages

* Significant at $P=0.0 \mathrm{I}$ or less using pooled error for $\mathrm{N}=6 \mathrm{r}$.

each of the 72 litters at birth, 21, 50 and roo days. Analyses of variance of litter weights of the kind given in table I, are presented in table 7. The results of these analyses are similar to those obtained with litter size, for the determination of both characters, from birth to maturity, 
is exclusively maternal (tables I and 7). This is in agreement with our earlier discussion in section (iii).

The highest yielding mothers come from strains $\mathrm{I}$ and 3 which produce both larger litters and heavy individual pups. The lowest yielders come from strain 5 which has both small litters and light pups.

\section{(v) Stability}

The strains used in these experiments are inbred (Broadhurst 1960). Four of them, strains 1, 2, 3 and 5 had been brother-sister mated for over 40 generations, one, strain 4 , for over 20 generations and the last, strain 6 for 8 generations only. Therefore, we would expect, the variation between individuals of like sex within the same litter to be predominantly non-heritable. Hence this variation may be used as a measure of developmental stability (Mather, I946, I953; Jinks and Mather, 1955). We can obtain the within sex, within litter variance for both sexes in each of the 72 litters at 50 and 100 days when all the animals were weighed individually and their sex recorded.

The magnitude of these variances for each sex at each age was independent of the means. For example, for males at 100 days the regression of within litter variance on litter mean was $b=-\mathrm{I} \cdot 28 \pm \mathrm{I} \cdot 54$ (difference from zero $\mathrm{P}=0 \cdot 5-0 \cdot 4$ ). An analysis of variance of the variances or $\log$ variances detected no significant differences which could be ascribed to heritable causes (Hayman, 1954). Similarly a Bartlett test could detect no heterogeneity in their magnitudes. As far as we can tell, therefore, the within litter variances are homogeneous over all litters for both sexes at each age. But, what is more important, the crossbred and inbred families in this diallel set of crosses do not differ significantly in the magnitude of this variance and hence do not differ in their developmental stability.

\section{(vi) Sex differences}

The two sexes are, within the sampling error, equally represented among the live births and among the animals surviving to maturity. They differ markedly, however, in body weight from weaning onwards and hence they make significantly different contributions to the litter weight (table 2). At weaning the average male is almost $2 \mathrm{gm}$. heavier than the average female and at maturity this difference has increased to almost $100 \mathrm{gm}$. In fact between birth and maturity the males, on average, gain weight I. 6 times faster than the females.

There is some indication that the relative weights of males and females vary from cross to cross (table 2 items $\mathrm{M} \times \mathrm{S}$ and $\mathrm{P} \times \mathrm{S}$ are significant). Males from reciprocal $F_{1}$ families do not differ more in body weight than females from reciprocal crosses or more than males from duplicate families. There is, therefore, no evidence that sexlinked genes are responsible for any part of the difference in body weight between sexes. 
The difference between sexes for body weight at maturity varies significantly from cross to cross. All the significant portion of this variation can be ascribed to differences between the maternal and paternal strains used in the crosses (table 3 ). The variation in the sex difference from cross to cross can, therefore, be subjected to a genetical analysis by the $\mathrm{Wr}, \mathrm{Vr}$ graph. The slope of the regression line is low $(b=0.62 \pm 0.18)$ but while it is significantly different from zero it is not significantly different from one. There is, therefore, no compelling reason for suspecting a failure of the assumptions underlying the following interpretation. Since the regression of $\mathrm{Wr}$ on $\mathrm{Vr}$ is significant, dominance is present and since the line passes close to the origin dominance is probably complete. The distribution of the array points on the $\mathrm{Wr}, \mathrm{Vr}$ graph is virtually identical with that for the body weight of males at Ioo days (fig. Ic). Strain 5 has the smallest sex difference and high values of $\mathrm{Wr}$ and $\mathrm{Vr}$; strain $\mathrm{I}$ has the greatest sex difference and low values of Wr and Vr. Hence the dominant alleles are preponderantly those which produce the greater sex difference.

Now, since we have ruled out sex linkage of genes controlling body weight the effects we have analysed must be ascribable to differences in the action of the same genes in the two sexes; that is, to sex limitation of gene action.

\section{(vii) Heterosis}

The inbred families produced, on average, $9 \cdot 42$ live births per litter which is higher but not significantly higher than the 9.29 live births per litter produced by the crossbred families. Since the determination of litter size is predominantly, if not exclusively, maternal (table I) we would expect the inbred and crossbred families to be the same, on average, for this character. Eighty-three per cent. of the individuals in the inbred litter survived to maturity compared with 88 per cent. of those in the outbred litters. Again this difference is not significant.

Since litter weight is also determined largely by the maternal strain (table 7) it is not surprising that the average weight of crossbred and inbred families at birth is virtually identical, being 50.23 and $5^{0} \cdot 75 \mathrm{gm}$., respectively. By maturity, however, the average litter weight of the crossbred families is $2008 \mathrm{gm}$. which is somewhat heavier than the inbred families average of $1883 \mathrm{gm}$. This difference can be accounted for almost entirely by the weights of the litters produced by mothers from the two strains which produce the heaviest litters (strains 2 and 5). These strains produce crossbred litters whose average weights are respectively I 72 and $462 \mathrm{gm}$. heavier than their inbred litters. In no case, however, are these crossbred litters heavier than those produced by the strains which provide the father. Hence there is no heterosis. Nevertheless the yield of offspring produced by the poorest yielding strains can be raised by outcrossing 
to males from higher yielding strains. Conversely, the yield of offspring of mothers from the higher yielding strains is almost constant irrespective of whether the father is from a high or a low yielding strain.

For individual body weight inbred and crossbred families, are on average, almost the same (table 2). At birth the average body weight of pups from inbred families is $5.38 \mathrm{gm}$. and for crossbred families $5.40 \mathrm{gm}$. At maturity the individual weights are 230.7 and $242 \cdot 0$ gm., respectively. The dominance which we have previously demonstrated for the genes controlling mature body weight must, therefore, be more often ascribable to alleles which increase than to alleles which decrease body weight. Animals from crossbred families are, in a few instances, heavier than those from their inbred parental families. For example, at all ages the rats from the cross $3 \times 4$ are heavier than those from inbred strains 3 or 4 . But neither this cross nor any other produces offspring which are consistently heavier than that of the heaviest inbred strain (strain I). Thus outcrossing occasionally produces heavier animals but no outcross is superior, in this respect, to the best available inbred strain.

On the transformed time scale the rate of growth of the inbred families on average is $38 \cdot 6$. and of the outbred families $4 \mathrm{I} \cdot 2$. This difference is not significant. In a few instances crossbred families are superior to both their inbred parents in rate of growth. But once again, no crossbred family is superior in rate of growth to the best inbred strain (strain I).

Over all, therefore, there is surprisingly little evidence of heterosis consequent on outcrossing these inbred strains of rats. Furthermore, there is no indication that the outbred animals are developmentally more stable than the inbreds.

\section{(viii) Comparison with earlier findings}

The only previous systematic study of the inheritance of a component of litter weight in rats is an investigation of the 91 day individual body weight in an incomplete diallel between 8 inbred strains (Craig and Chapman, 1953). Since twelve crosses necessary to complete the diallel are missing an analysis of the kind we have carried out is impossible. Craig and Chapman, however, were able to draw a number of conclusions from their analyses which we can compare with our own.

By arguments similar to those we have used, Craig and Chapman concluded that sex linkage, maternal effects and litter size have no effect on adult body weight. Our own data are in agreement. They also concluded that while the average adult individual body weight of crossbred animals is slightly heavier than the average inbred parents there is no superiority over the better parents. By comparing the inbred parental strains with the outbred stocks obtained from the same outbred foundation stock Craig and Chapman have shown that 
there is no inbreeding depression for body weight. These conclusions are again in complete agreement with our own.

While Craig and Chapman speculate about the cause of the deviation of the outbred animals from the mid parent values and suggest dominance and overdominance of the alleles for greater body weight, their analyses did not extend to the level of gene action. We have shown that the absence of heterosis coincides with the absence of all the usual causes of heterosis, namely non-allelic interactions and a predominant dispersion of the genes controlling body weight. We have further shown that body weight is controlled by genes with additive and dominance effects, whose actions are subject to sex limitation and which are randomly distributed among the parental strains. And we have distinguished those strains which contain most and least dominant alleles. One final conclusion of Craig and Chapman is that heritability is between 40 and 50 per cent. Estimated in the same way, that is by parent offspring correlations, our data yield similar values (see section (ix) below). However, we believe the component analysis in table 4 to be more informative. It shows that the heritable components of variation for body weight at maturity $\left(D, H_{1}, H_{2}\right.$ and $\left.F\right)$ are higher than that ascribable to environmental causes $(\mathrm{E})$.

Where they overlap, therefore, our results are in substantial agreement with the only earlier ones found in the literature. Our analytical approach, however, has allowed us to pursue the interpretation further.

\section{(ix) Predicting the outcross performance}

It is the usual experience with outbreeding species that, while the relative performance of outcrosses is significantly and positively correlated with that of the inbred parental lines from which they were derived, this correlation is small. Hence, prediction of the outcross performance from that of their inbred parents is poor. A higher correlation and hence a better prediction of the performance of outcrosses is usually obtained only if account is taken of the performance of related outcrosses, for example, other outcrosses in the same maternal and paternal arrays.

This is the case in both Craig and Chapman's and in our own experiments. In the latter the correlation between adult body weight of the outcrosses and that of their mid-parents is 0.55 , but the correlation with the mean body weight of outcrosses in the same maternal and paternal arrays is 0.85 . Thus we cannot make a worthwhile prediction of the relative adult body weights of rats from outcross families from that of the inbred strains without first knowing the performances of related outcrosses. This we would expect because of the presence of non-additive gene effects for this character (section ii).

Litter size is maternally determined. Excellent prediction of the litter sizes of the outcrosses can therefore be expected from that of the 
inbred maternal strains. The correlation is $0.9 \mathrm{I}$ and so this expectation is realised.

There are obvious economic advantages, not realisable in this instance, in being able to predict the performance of outcrosses from those of the inbred parents. There are similar advantages in predicting adult performance from that at an earlier age. The correlation between body weights at different ages given in table 6 show that useful predictions of adult body weight cannot be made until rats are at least 50 days old. Selection for body weight before this age would therefore be little better than random culling with respect to adult body weight.

\section{CONCLUSIONS AND SUMMARY}

Our investigation of the inheritance of litter size and body weight of domestic rats by diallel analysis has shown the following.

I. Litter size is maternally determined at birth and there are no differences in survival to maturity among litters.

2. Individual body weight at birth and maturity is largely determined by the individual's own genotype. At weaning it is determined entirely by causes external to the individual's genotype and for a short period after weaning it has a strong maternal component. Among the external causes are maternal care and litter size between birth and weaning.

3. There are no more differences in the sex ratio among litters than expected from sampling variation alone. A sex difference in body weight is due to the sex limitation of gene action rather than to sex-linked genes.

4. The heritable component of individual body weight consists of both additive and dominance effects. There is no evidence of nonallelic interactions, overdominance or correlated gene distributions.

5. Either the dominance relationships of the genes controlling body weight change with age, or, different loci control this character at different ages.

6 . The linear rate of increase in individual body weight between birth and maturity measured on a transformed time scale has a significant heritable component which contains both additive and dominance effects.

7. There is no heterosis for litter size and almost none for body weight and total litter weight. For all characters, the best litter from the inbred strains was not exceeded by any outcross.

8. The relative body weights of individuals in the outcrossed families cannot be predicted from those of the inbred strains from which they arose. An improved prediction was achieved by using the performance of related outcrossed families from the same arrays. Adult body weight is almost independent of the body weight at birth and weaning. There are therefore, no short cuts to the selection of outcrosses for their adult body weight. 


\section{REFERENCES}

BROADHURST, P. L. 1959. Application of biometrical genetics to behaviour in rats. Nature, London, $184,1517-1518$.

BROADHURST, P. L. 1960. Experiments in Psychogenetics. Applications of biometrical genetics to the inheritance of behaviour, I-102. In Eysenck, H. J. (Ed.). Experiments in Personality. I. Psychogenetics and Psychopharmacology. Routledge and Kegan Paul, London.

BROADHURST, P. L. I96 I. Analysis of maternal effects in the inheritance of behaviour. Anim. Behav., 9, 129-141.

BRUMBY, P. J. 1960. The influence of the maternal environment on growth in mice. Heredity, I3, I-I8.

CRAIG, J. V. AND CHAPMAN, A. B. 1953. Experimental test of predictions of inbred line performance in crosses. Fourn. of Anim. Sci., I2, I 24-1 39 .

hayman, B. I. 1954a. The analysis of variance of diallel crosses. Biometrics, ro, $235-244$.

hayman, B. 1. 1954b. The theory and analysis of diallel crosses. Genetics. 39, 789-809.

JINKS, J. L. I954. The analysis of continuous variation in a diallel cross of Nicotiana rustica varieties. Genetics, 39, 767-788.

Jinks, J. L. AND hayman, B. I. I953. Analysis of diallel crosses. Maize Genetics Cooperation News Letter, 27, 48-54.

JINKS, J. L. AND MATHER, $\mathrm{K}$. 1955. Stability in development of heterozygotes and homozygotes. P.R.S.B., I43, 561-578.

MATHER, K. I946. The genetical requirements of bio-assays with higher organisms. The Analyst, 7I, 407.

MATHER, K. 1953. Genetical control of stability in development. Heredity, 7, $297-336$. 